\title{
Evolution of Japan Manufacturing Foundation: Dual Global Engineering Model Surpassing JIT
}

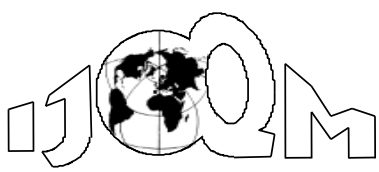

DOI: $10.46970 / 2020.26 .2 .3$

\author{
Kakuro Amasaka \\ Aoyama Gakuin University, Japan \\ (amasaka@mics.ne.jp)
}

Volume 26, Number 2

June 2020, pp. 121-146

Today, the digital engineering is bringing about radical changes in the manufacturing way and is carried out at manufacturing sites. To advance the Japan manufacturing foundation, this study mentions the New Japan Production Management Model (NJ-PMM) that surpasses conventional JIT practices in order to re-construct world-leading management technologies. On a concrete target, the author focuses on the strategic development of Dual Global Engineering Model (DGEM) by possessing the New Japan Global Production Model (NJ-GPM) and New Japan Global Manufacturing Model (NJ-GMM) surpassing JIT. The effectiveness of DGEM was verified through the actual applications to automobile manufacturing in Toyota and suppliers.

Keywords: Japan manufacturing foundation, Dual Global Engineering Model, New Japan Global Production Model, New Japan Global Manufacturing Model, surpassing JIT, Toyota and suppliers

\section{Introduction}

Recently, Japanese Production System, which is typified by the Toyota Production System (TPS) has been further developed and spread in the form of internationally shared global production systems such as Just in Time (JIT), and therefore it is no longer a proprietary technology of Japan (Ohno, 1977; Womack et al., 1990; Amasaka, 1988, 2002, 2007a). Furthermore, today, digital engineering is bringing about radical changes in the way manufacturing is carried out at manufacturing sites (Amasaka, 2007b; Amasaka, Ed., 2007; Amasaka and Sakai, 2010).

To overcome this issue, it is now necessary to re-construct world-leading management technologies so that they will be viable even for the next generation of automobile manufacturing which is represented by the Total Production System based on core principle for the New Manufacturing Theory (NMT) based on New JIT principle (Amasaka, 2002, 2007a, 2014, 2019a, 2020a; Amasaka et al., 2008). By concrete deployment for automobile global production employing NMT, the author has created the New Japan Production Management Model (NJ-PMM) in Toyota.

With this mind, as the keys to successful global production, this study mentions the evolution of Japan manufacturing foundation in order to advance NJ-PMM that surpasses conventional JIT practices. On a concrete target, the author focuses on the strategic development of Dual Global Engineering Model (DGEM) by possessing the New Japan Global Production Model (NJ-GPM) and New Japan Global 
Manufacturing Model (NJ-GMM) surpassing JIT (Amasaka and Sakai, 2011; Amasaka, 2020a). The aim of DGEM is to realize a highly reliable production system suitable for global production by reviewing the production process from production planning, preparation and manufacturing through production itself and process management.

Specifically, first, six core management technologies of NJ-GPM consist of the TPS Layout Analysis System (TPS-LAS), Human Intelligence-Production Operating System (HI-POS), TPS Intelligent Production Operating System (TPS-IPOS), TPS Quality Assurance System (TPS-QAS), Human Digital Pipeline (HDP), and VirtualMaintenance Innovated Computer System (V-MICS) (Amasaka and Sakai, 2011). Similarly, second, six core management technologies of NJ-GMM consist of the Intellectual Working Value Improvement Management Model (IWV-IMM), Partnering Performance Measurement Model (PPMM), Strategic Stratified Task Team Model (SSTTM), Intelligence High-cycle System of Assembly Maker Production Process (IHS-AMPP), Strategic Quality Management using Performance Measurement Model (SQM-PMM), and Working Value Evaluation Model (WVEM).

Concretely, the author has verified the effectiveness of DGEM through the actual applications of automobile manufacturing in Toyota and suppliers (Amasaka et al., 2008; Amasaka, 2015, 2017a, 2019a, 2020b; Amasaka, Ed., 2012, 2019).

\section{Needs for Advances in Global Manufacturing Engineering}

\subsection{The Demand for Advances in Manufacturing Technology}

The environmental changes that surround today's manufacturing industry are truly severe. It is vital for Japanese manufacturing not to fall behind in the advancement of management technologies. For manufacturers to succeed in the future world market, they need to continue to create products that will leave a strong impression on customers and to offer them in a timely fashion (Amasaka, 2002).

At present however, the TPS which is representative of Japanese manufacturing, has been further developed and spread in the form of internationally shared global production systems such as JIT and Lean System and therefore it is no longer a proprietary technology of Japan (Hayes and Wheelwright, 1984; Doos et al., 1991; Womack and Jones, 1994; Taylor and Brunt, 2001). It is not an exaggeration to say that what will ensure Japanese manufacturers' success in global marketing is the realization of simultaneous achievement of QCD (quality, cost and delivery)-ahead of their competitors (Amasaka, 2004a, 2007a,b, 2008).

The urgent mission for Japanese manufacturers is to reconstruct world-leading, uniquely Japanese principles of management technology, which will be viable even for next-generation manufacturing as the evolution system of JIT (Amasaka et al., 2008; Amasaka, 2009, 2014; Amasaka and Sakai, 2010). To prevail in today's competitive manufacturing industry, which is often referred to as a worldwide quality competition, the pressing management issue is to realize the kind of global production that can achieve called the "worldwide uniform quality and production at optimal locations" (Amasaka and Sakai, 2011; Amasaka, 2015, 2018).

\subsection{Innovation of Japan's Global Manufacturing Fundamentals}

To offer customers high value-added products and prevail in the worldwide quality competition, it is necessary to establish an advanced production system that can intellectualize the production engineering and manufacturing management system. 
This will in turn produce high performance and highly functional new products. The author believes that what determines the success of global production strategies is the advancement of technologies and skills that are capable of fully utilizing the above mentioned advanced production system in order to realize reliable Japan's global manufacturing fundamentals at the production sites (Amasaka, 2007a).

Then, the author posed the question, "What are some of the issues that need to be addressed in order to prevail in the 21 st century?" to a total of 154 respondents chosen from the top management class (board members) and managers (of divisions and departments) of the six manufacturers that participated in the "Workshop on Quality Management of Manufacturers" (hosted by Kakuro Amasaka, Professor of Aoyama Gakuin University from May 2004 to March 2006). The survey revealed the interests of the top management and manager classes (Amasaka Ed., 2007). Figure 1 is an example of the summary and analysis results of these interests (or the free opinions gathered from the survey). As shown here, their interests center on technological development, human resources development, globalization, product differentiation, quality, safety, organization, and management.

Consolidating these items, the management technology issue that they commonly share is the establishment of the kind of global production system that can achieve worldwide uniform quality and simultaneous launch (production at optimal locations). Among other things, what they give top priority to is the realization of manufacturing with high quality assurance. This is achieved through high cycleization of the business process related to manufacturing at overseas production plants (or production sites) in industrialized nations in the West or developing nations, not to mention in the Japanese domestic market. In particular, they are concerned about the current situation in which the production sites are undergoing drastic changes due to the use of digital engineering and IT (Information Technology). Moreover, it was seen as critical to realize the intellectualization of the production sites so that they do not lag behind the advancements being made in technology and skills.

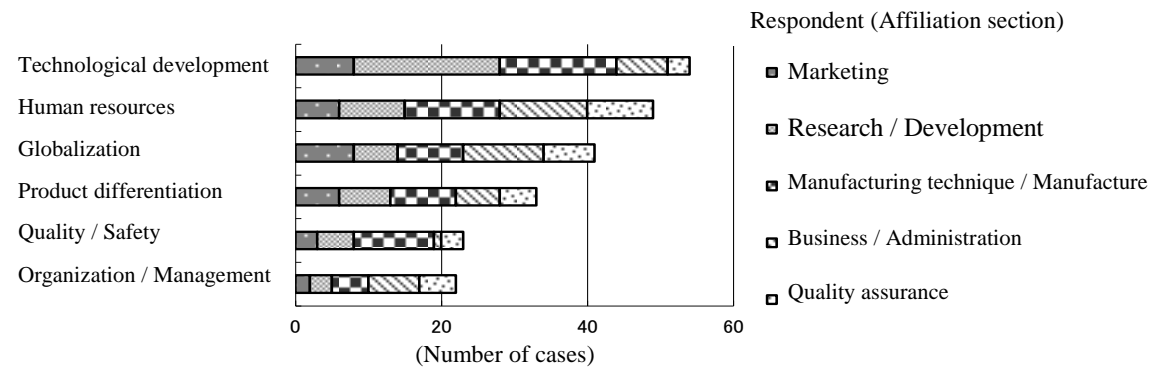

Figure 1 What is the Important Issue which should be Tackled?

\section{Evolution of Japan Manufacturing Foundation Surpassing JIT}

3.1 Creation of Total Production System based on New Manufacturing Theory

To develop the Advances in Global Manufacturing Engineering above, the author has created the Total Production System which is one of core principles of the New Manufacturing Theory (NMT) called New JIT, new management technology principle (Amasaka and Sakai, 2011; Amasaka et al., 2008; Amasaka, 2014, 2019a).

In Figure 2, the aim of Total Production System is to enable a focus on customers and employees as well as the reinforcement and improvement of production process control through incorporation of four sub core elements as follows; (a) production 
based on information to require the reformation of the production philosophy, (b) production based management to reform the workplace configuration, (c) Production based on engineering to reinforce the production technology and (d) production based on workshop formation to create the highly creative and active workplace.

(b) Production based on management

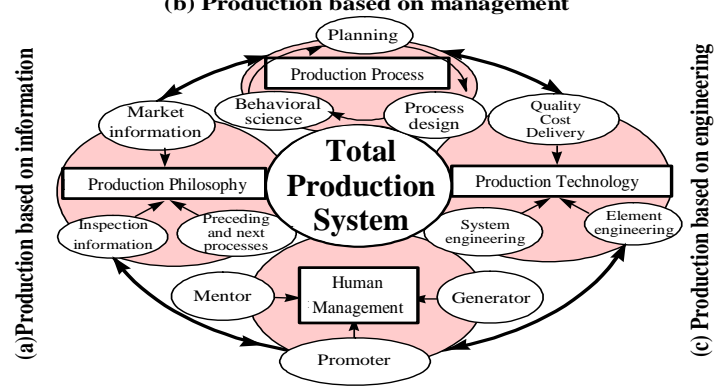

(d)Production based on workshop formation

Figure 2 Schematic Drawing of Total Production System

\subsection{Developing New Japan Production Management Model (NJ-PMM) surpassing JIT}

To develop NMT, furthermore, the author has developed the New Japan Production Management Model (NJ-PMM) called Advanced TPS surpassing JIT in order to enable the strategic deployment of Total Production System and SCM (Supply Chain Management) (Amasaka, 2007a,b, 2008, 2019a; Amasaka and Sakai, 2010, 2011). In Figure 3, the mission of NJ-PMM is to contribute the worldwide uniform quality and production at optimal locations as the strategic deployment of global production and to realize Customer Satisfaction (CS), Employee Satisfaction (ES), and Social Satisfaction (SS) through high quality assurance manufacturing.

On a concrete target, this model is the systemization of a new, next-generation Japanese production management system and this involves the high-cyclization of the production process for realizing the simultaneous achievement of QCD requirements. To make this model into a reality it will be necessary to adapt it to handle digitalized production and reform it to realize a renewal production

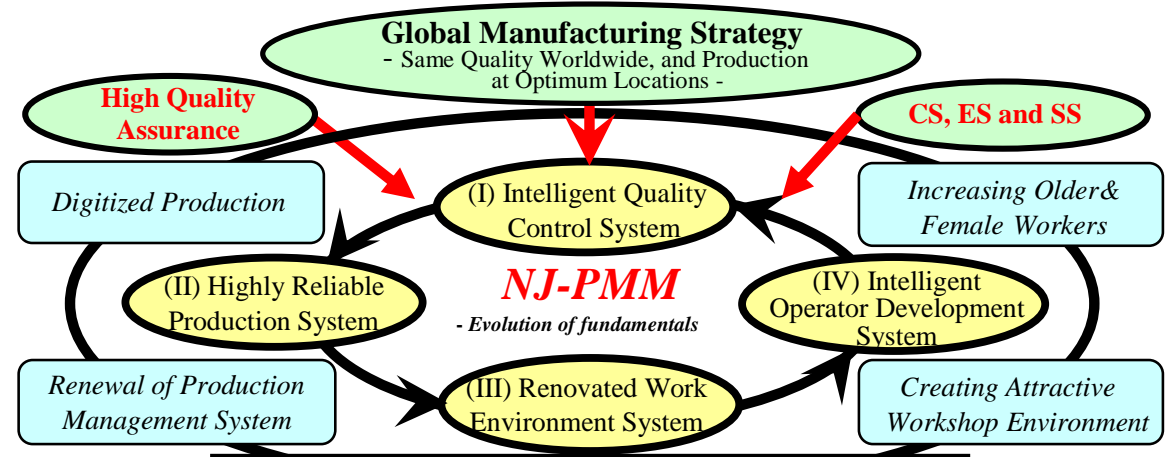

Key to strategic application of Total Production System

Figure 3 Schematic Drawing of New Japan Production Management Model (NJ-PMM) 
management system. Moreover, other prerequisites for realizing this include the need to create an attractive working environment that can accommodate the increasing number of older and female workers at the production sites and to cultivate intelligent production operators.

One of the technical elements necessary for fulfilling these requirements is the reinforcement of maintenance and improvement of process capabilities by establishing an intelligent quality control system. Second, a highly reliable production system needs to be established for high quality assurance. Third, reform is needed for the creation of a next generation working environment system that enhances intelligent productivity. Fourth, intelligent production operators need to be cultivated that are capable of handling the advanced production system and an intelligent production operating development system needs to also be established.

\section{Dual Global Engineering Model (DGEM) to Advance NJ-PMM}

Then, to advance NJ-PMM, the author has created the Dual Global Engineering Model (DGEM) by processing the New Japan Global Production Model (NJ-GPM) and New Japan Global Manufacturing Model (NJ-GMM) as the dual global engineering on the production plan, production preparation, manufacturing, inspection and SCM.

\subsection{New Japan Global Production Model (NJ-GPM)}

Global production must be deployed in order to establish the kind of manufacturing that is required to gain the trust of customers around the world by achieving a high level of quality assurance and efficiency and shortening lead times to reinforce the simultaneous achievement of QCD requirements. The vital key to achieving this is the introduction of a production system that incorporates production machinery automated with robots, skilled and experienced workers (operators) to operate the machinery and, further, production information to organically combine them.

Thus, having recognized the need for a new production system suitable for global production, the author has created the New Global Production Model (NJ-GPM) to realize the strategic deployment of the NJ-PMM above (Amasaka and Sakai, 2011). In Figure 4, the purpose of this model is to eradicate ambiguities at each stage of the production process as the production planning and preparation through production itself and process management, and between the processes in order to achieve a highly reliable production system for global production which will improve the reliability of manufacturing through the clarification and complete coordination of these processes.

More specifically, the model is intended to (i) employ numeric simulation (Computer Aided Engineering, CAE) and computer graphics (CG) right from the production planning stage to resolve technical issues before they occur, (ii) reinforce production operators' high-tech machine operating skills and manufacturing capabilities, and (iii) visualize the above using IT in order to reform production information systems to create a global network of production sites around the world.

The six core management technologies that constitute this model and their characteristics are described below (Amasaka, 2017a, 2020b).

1. Reform of production planning: TPS Layout Analysis System (TPS-LAS) is a production optimization intended to realize a highly reliable production system. 


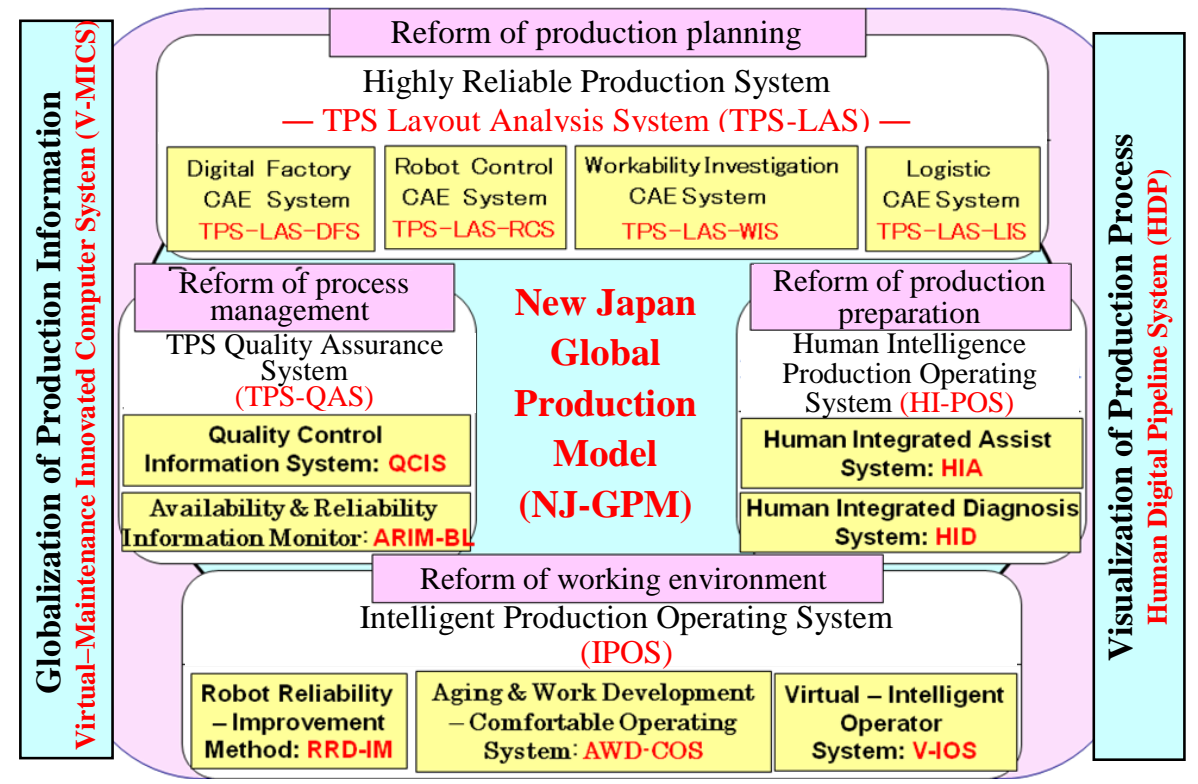

Figure 4 New Japan Global Production Model (NJ-GPM)

by optimizing the layout of both the production site as a whole and each production process with regard to production lines (logistics and transportation), robots (positioning), and production operators (allocation and workability) through the use of numeric simulation (Sakai and Amasaka, 2006a).

2. Reform of production preparation: Human Intelligence - Production Operating System (HI-POS) is an intelligent operator development system intended to enable the establishment of a new people-oriented production system whereby training is conducted to ensure that operators develop the required skills to a uniform level, and diagnosis is then carried out to ensure that the right people are assigned to the right jobs (Sakai and Amasaka, 2006b). HI-POS is made up of two sub-systems: Human Integrated Assist System (HIA) and Human Intelligence Diagnosis System (HID).

3. Reform of the working environment: Intelligent Production Operating System (IPOS) is intended to lead to a fundamental reform of the work involved in production operations by raising the technical skills level of production operators and further improving the reliability of their skills for operating advanced production equipment within an optimized working environment. TPS-IPOS is made up of three sub-systems: Virtual - Intelligent Operator System (V-IOS), Aging \& Work Development - Comfortable Operating System (AWD-COS), and Robot Reliability Design - Improvement Method (RRD-IM) (Sakai and Amasaka, 2003, 2007a; Amasaka, 2007c).

4. Reform of process management: TPS Quality Assurance System (TPS-QAS) is an integrated quality control system intended to ensure that quality is built into production processes through scientific process management that employs statistical science to secure process capability $(\mathrm{Cp})$ and machine capability $(\mathrm{Cm})$ (Amasaka and Sakai, 1998, 2009). TPS-QAS is made up of two sub-systems: 
Quality Control Information System (QCIS) and Availability \& Reliability Information Monitor System (ARIM).

5. Visualization of production processes: Human Digital Pipeline System (HDPS) ensures that top priority is given to customers through manufacturing with a high level of quality assurance (Sakai and Amasaka, 2007b). This involves the visualization of intelligent production information throughout product design, production planning and preparation, and production processes, thereby facilitating the complete coordination of these processes. This system enables the high-cyclization of business processes within manufacturing.

6. Globalization of production information: Virtual - Maintenance Innovated Computer System (V-MICS) is a global network system for the systemization of production management technology necessary to realize a highly reliable production system, which is required to achieve worldwide uniform quality and production at optimal locations (Sakai and Amasaka, 2005).

\subsection{New Japan Global Manufacturing Model (NJ-GMM)}

To be successful of global manufacturing in the near future, the Japanese manufacturing industry must develop an excellent manufacturing management technology employing the advances in manufacturing engineering that can continuously provide high value products in a timely manner surpassing "Kaizen" (improvement) of manufacture site symbolized by TPS based on the three actuals of the actual place, actual part and actual situation (Amasaka, 1988, 2009). Moreover, a key of global manufacturing is the systematic deployment of SCM on a global scale that encompasses cooperative manufacturing operations with overseas suppliers employing a newly global partnering model (Amasaka, 2004a, 2008; Ebioka et al., 2007).

To realize the world uniform quality-simultaneous model launches, the author has created the New Japan Manufacturing Management Model (NJ-GMM) by using six core models based on the structure of manufacturing engineering as shown in Figure 5 (Amasaka, 2020a). In NJ-GMM, the main characteristics of each core model contribute to the advancement of manufacturing management through actual QCD research by using statistical science, as follows (Amasaka, 2017a, 2020b);

1. Intellectual Working Value Improvement Management Model (IWV-IMM) as the basic principle of working value intends that the design, production, quality assurance, marketing, human resource development, and administration cooperate and must reform the technologies and skills of the workers for the revolution of operating technology and skill in workplaces (Yamaji et al., 2007a; Tsunoi et al., 2010). In particular, boosting morale, reduction of fatigue, development of physical strength, development of tools \& devices, improvement of thermal environment, and prevention of illness \& injury are required for evolution.

2. Partnering Performance Measurement Model (PPMM) for assembly makers and suppliers serves as a formulation model using radar chart for visualization for evaluating the actual status of Japanese partnering between automobile assembly makers and parts suppliers, which has been somewhat implicitly carried out in the past (Yamaji et al., 2008). In connection with the PPMM development, the author creates PPMM-A for assembly makers, PPM-S for suppliers, and PPMAS for assembly makers and suppliers, as a comprehensive dual performance 


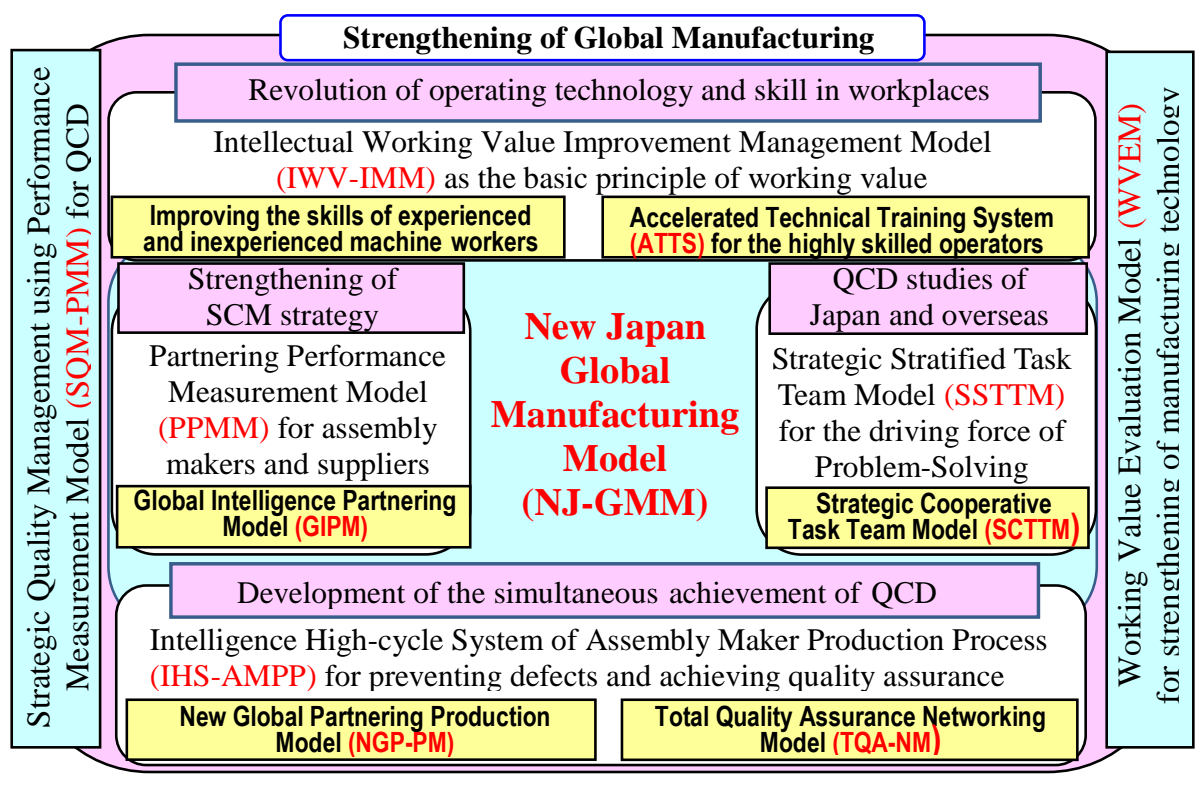

Figure 5 New Japan Global Manufacturing Model (NJ-GMM)

measurement.

3. Strategic Stratified Task Team Model (SSTTM) for the driving force of problemsolving contributes to the strengthening of the ties among group manufacturing companies, non-group companies, and even overseas manufacturers (suppliers) (Amasaka, 2004a,b, 2008). To realize this, the level of problem-solving technology rises in product development strategy I and II through joint task teams of intra-company departments and divisions (Task-1 to Task-6, Group task team, Department task team, Division task management team, Field task management team, Total task management team) called "Internal Partnering". This technology is further expanded to quality management strategy I to II through the domestic affiliated company, domestic non-affiliated company, and overseas non-affiliated company (Task- 6 to Task-8, Joint A to Joint C) called "External Partnering".

4. Intelligence High-cycle System of Assembly Maker Production Process (IHSAMPP) for preventing defects and achieving quality is effective management of the advanced production process (Amasaka et al., 2008; Amasaka and Sakai, 2010; Amasaka, 2018). To improve the intelligent productivity of production operators and to consolidate the information about highly cultivated skills and operating skills, IHS-AMPP contains the advanced facilities into commonly shared fore core systems as follows; (I) Highly Reliable Production System (HRPS), (II) Intelligent Quality Control System (IQCS), (III) Renovated Work Environment System (RWES), and (IV) Intelligent Operators Development System (IODS).

5. Strategic Quality Management using Performance Measurement Model (SQMPMM) is the criterion of strategic development of NJ-GMM. At a stage of creation of SQM-PMM, specifically, and a survey of top management at 
Japanese manufacturers was conducted in order to investigate the management achievements as a key to strategic global manufacturing (Survey targeted 898 companies) (Amasaka et al., 1999; Amasaka, 2009; Kozaki et al., 2012). First, the author conducted the graphical modeling method based on the correlations among the 28 practice items of six categories-TQM methods, technological development, CS, quality assurance, corporate culture, and total participation activities. Second, the author performed the formulation of SQM-PMM through canonical correlation analysis. Moreover, the author verified the validity of SQM-PMM standardization.

6. Working Value Evaluation Model (WVEM) for strengthening of manufacturing technology makes the basic of "Creative workplace" as moving power of SQMPMM, and evaluates the awareness of the working value of workers by statistically analyzing data collected through actual condition survey on Toyota, Nissan and other three companies (Uchida et al., 2012). This model systematically covers 20 key factors based on the fatigue reduction, disease prevention, comfort, organizations, and intelligence ability. Then, the author received 25 sets of answers from workers in the manufacturing industry, and analyzed their weightings using covariance structure analysis. Also, standardization of evaluation formulas made it possible to compare the strength of each working value evaluation axis in order to deployment and verify the validity of WVEM.

\section{Application Examples}

In this section, the author illustrates some research examples of Toyota's pioneering technology as applications of the NJ-PMM based on the NMT. NJ-PMM is contributing to the advancement of automobile management technology at Toyota and suppliers by developing DGEM with NJ-GPM and NJ-GMM, and is proving to be effective both in Japan and overseas (Amasaka and Sakai, 2011; Amasaka, 2015, 2017a, 2018, 2019a, 2020a,b).

\subsection{Innovation of Automobile Production Engineering based on the NJ-GPM}

(1) Production planning employing TPS-LAS, HDPS and HI-POS

In TPS-LAS application based on production engineering, the author has developed a simulation of main body conveyance using its four constitute sub-systems ((i)-(iv)) to illustrate a highly liable production process that has contributed to the reform of production planning as shown in Figure 6 (Sakai and Amasaka, 2006a).

Firstly, specifically, a hypothetical production line is set up within a "digital factory" on a computer. (i) TPS-LAS-DFS is then used to reproduce the flow of people and parts within the production site. This enables any interference between production machinery and production cycle times to be checked in advance using simulations. One type of advance simulation uses (ii) TPS-LAS-RCS for the optimum placement of welding robots for the main body to ensure that no interference occurs. Next, advance verification is performed using (iii) TPS-LASWIS to ensure that the predetermined work (standardized work) is carried out within the predetermined cycle time with no waste (muda) or overburdening (muri). Then, (iv) TPS-LAS-LIS is used to establish optimized conveyance routes between processes and determine optimum buffer allocations. 


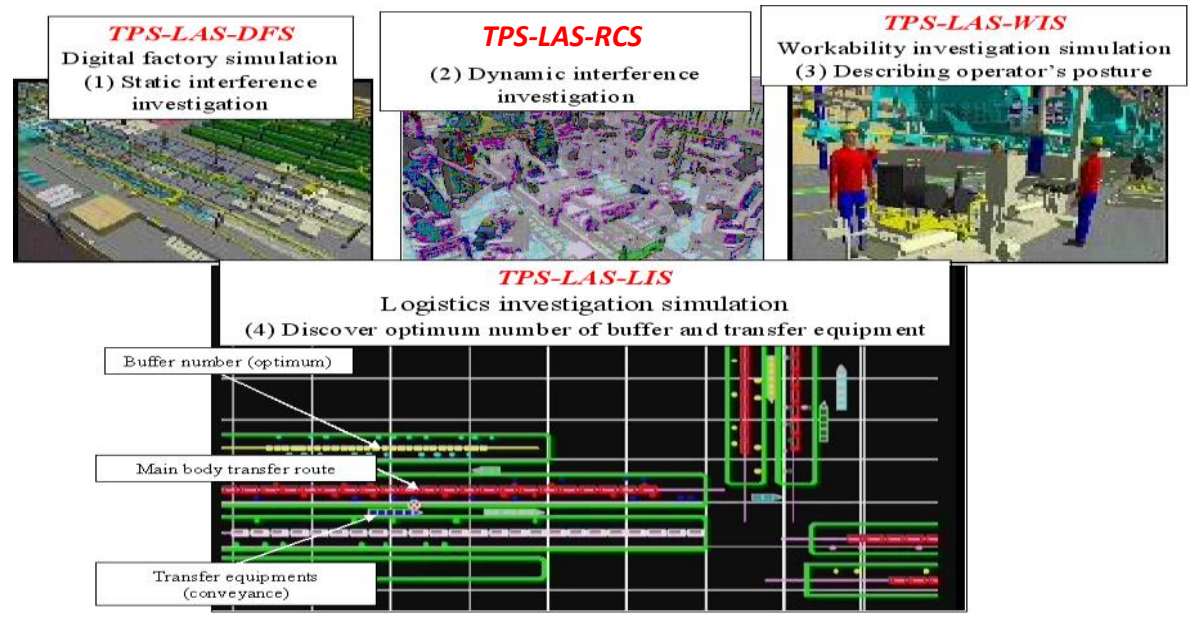

Figure 6 TPS-LAS, Developing the Simulation of Main Body Conveyance

In addition, in HDP system application using production engineering, the author has carried out the image training of production processes in actual order of automobile assembly operations in order to the innovation of production planning as shown in Figure 7 (Sakai and Amasaka, 2007b). To intellectual training, this is done at the preparatory stage before beginning mass production without having a real product on hand. HDP promotes the leveling of the workload of operators in each process $_{2}$ and then completes the building up of production line even before launching it using Total Linkage System (TLS) of intellectual production information through the product design, production engineering and manufacturing.

Firstly, specifically, HDP creates and supplies in advance "Standard Work Sheets" on which production operators have recorded each task in the correct order for jobs such as assembly work, by using design data for new products and facilities prepared from design through to production technology, even if there are no production prototypes. Next, HDP enables visualization training for machining processes stepby-step in the order that parts are built up, even if the actual product does not yet exist. This system is proving to be very effective in raising the level of proficiency

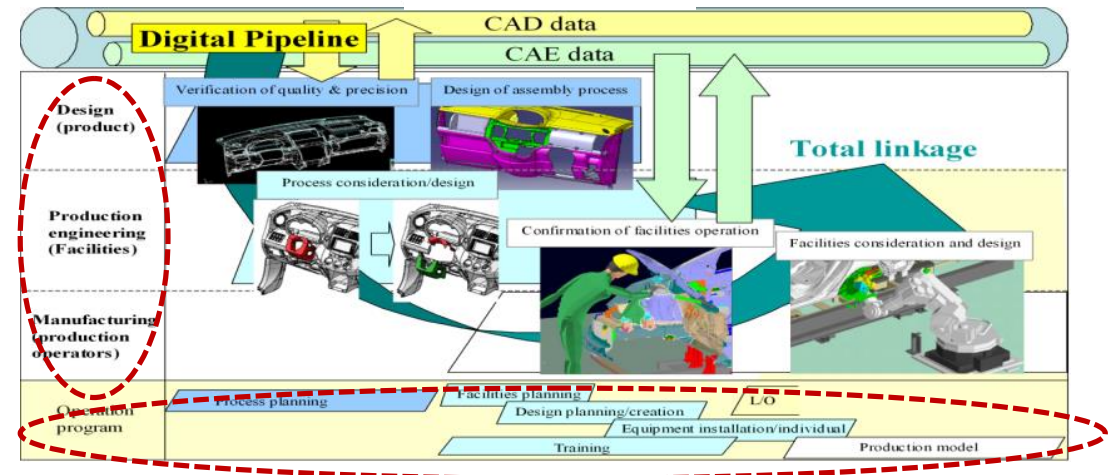

Figure 7 HDP System, Raising the Level of Skills and Capabilities 


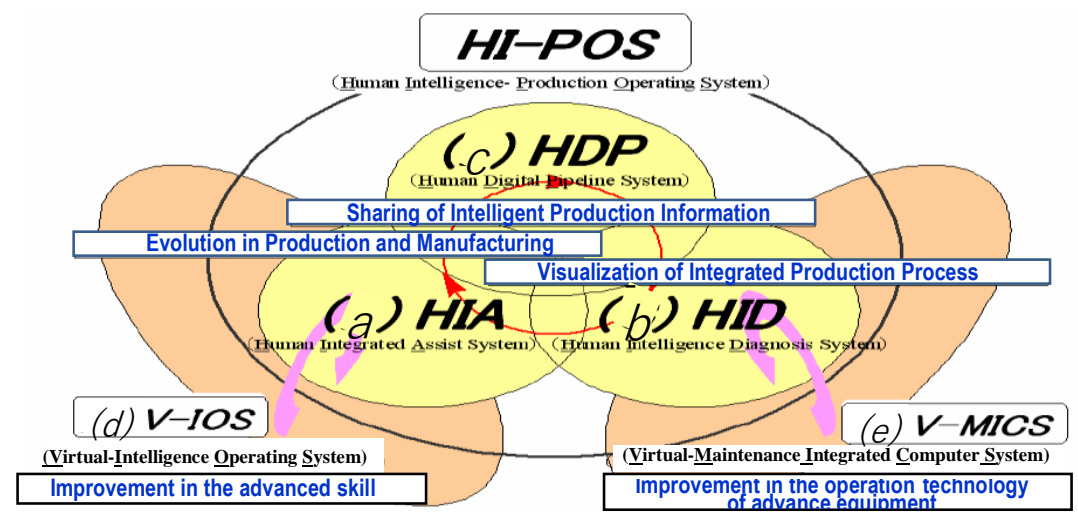

Figure 8 HI-POS, Strengthening of the Intelligent Operator Development System

for processes requiring skills and capabilities at the production preparation stage.

Furthermore, in HI-POS application employing production engineering, the author has created the intelligent operator development system intended to establish a new people - oriented production system as shown in Figure 8 (Sakai and Amasaka, 2003, 2005, 2006b, 2007a,b, 2008). Firstly, the author has developed three constituent subsystems-(a) HIA for the evolution in production and manufacturing, (b) HID for the visualization of integrated production process based on the above (c) HDP for the sharing of intelligent production information. Next, to strengthen the integration of HI-POS, this system is integrated with two support systems-the following (d) V-IOS for the improvement in the advanced skill, and (e) V-MICS for the improvement in the operation technology of advance equipment. The combined applications of TPSLAS, HDP and HI-POS are currently being contributed as a part of global production, and proving to be effective both in Japan and overseas.

(2) Production preparation employing V-MICS, IPOS and TPS-QAS

Furthermore, the author has developed the production preparation for the strengthening of production process employing V-MICS, I-POS and TPS-QAS.

First, V-MICS takes a server and client system configuration employing DB (data base) and CG in order to browse information whenever necessary from the client computers at each maintenance station via the network, and can also input any special items as necessary as shown in Figure 9 (Sakai and Amasaka, 2005). In VMICS application using HDP, TPS-LAS, HI-POS, V-IOS and RRD-IM, the author has developed combining both the (i) Production Process Optimization Simulation (PPOS) and (ii) Work Operation Combination Simulation (WOCS) for the high productivity (Sakai and Amasaka, 2007a,b).

(i) PPOS shows the verification of the operators interfering with one another when determining which combinations of vehicle models cause the overlapping of operators in the time series in order to evaluation and problem finding as shown in Figure 10. This is an aerial view of the process in which a vehicle is carried on the conveyor at a fixed speed, and the walking routes of the operators performing assigned work operations are displayed in real time in straight lines.

When multiple operators performing different operations in one process are 

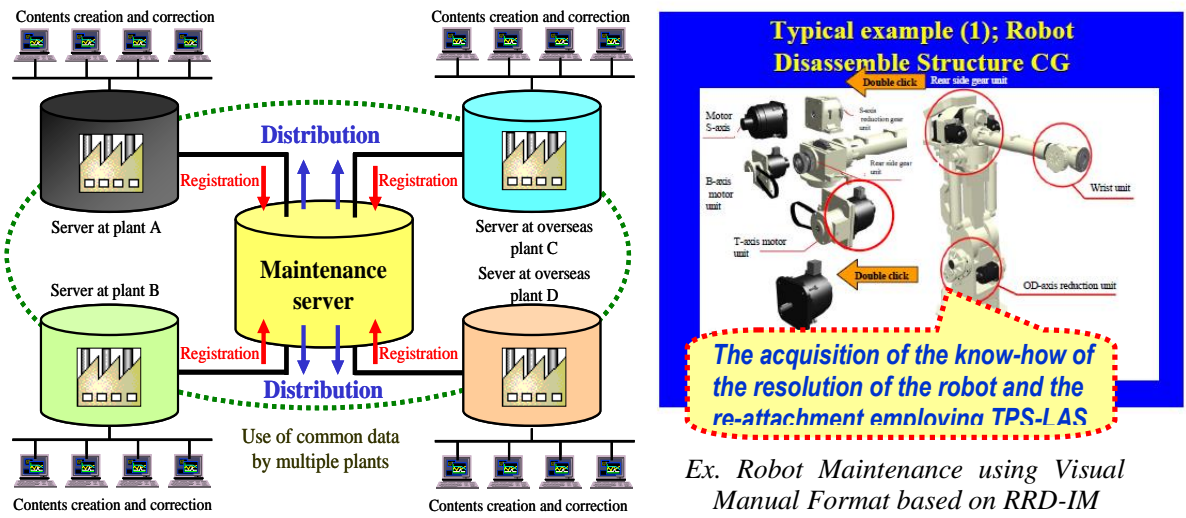

Figure 9 V-MICS, Systematizing Managerial Technique of Production Facilities

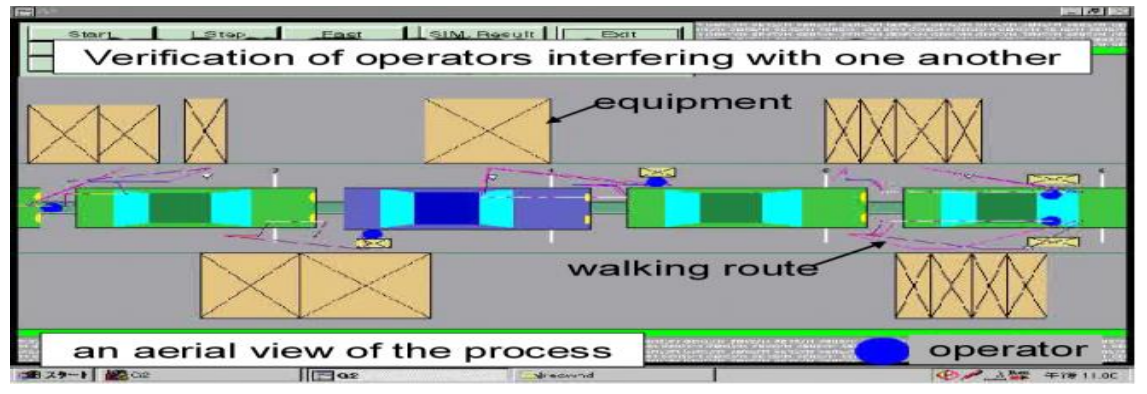

Figure 10 PPOS Example of Verification of Operators' Interfering with One

overlapped (that is when operators' interference occurs), it is displayed instantly, and the information on which combination of models is also output immediately. Verification will be conducted through simulation as to whether operators can complete their entire operation of one process in the set "Takt-Time" and "Heijunka" (Amasaka, 1988, 2009). Based on the simulation, verification results are displayed showing which process, on which vehicle model, caused the operator to stop the conveyor.

(ii) WOCS can be carried out in the real Takt-Time based on Heijunka. In Figure 11 (left), by sorting out the working time and walking time from the accumulated time results, the uneven distribution of the net-working time and the non-working time, such as time spent walking, are stratified to serve as a guideline for reviewing the process layout. Then, Figure 11 (right) shows the re-calculation of the work accumulation after reshuffling the basic work operations between processes. Such changes can be easily made on the accumulative simulation screen by dragging and dropping with the mouse, immediately confirming the work points of previous and subsequent operations while automatically adjusting the walking time involved.

Second, to employ I-POS strategically, the author has developed the (i) V-IOS, (ii) RRD-IM and (iii) TTD-IM employing HDP, HI-POS and TPS-LAS.

(i) V-IOS and (ii) RRD-IM using HID and Visual Manual is intended to improve the skills of new (inexperienced) production operators both in Japan and overseas. In 


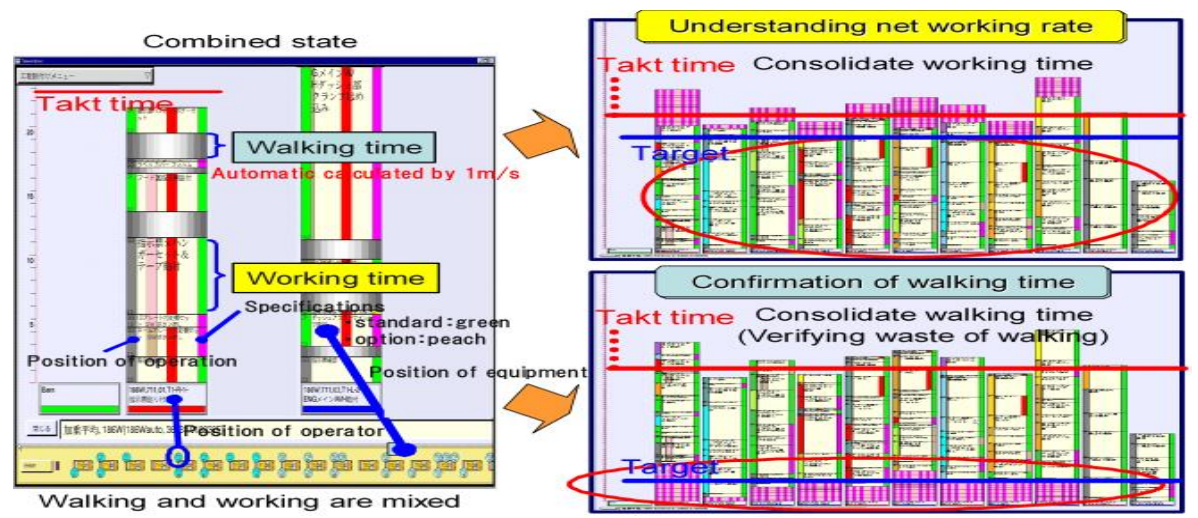

Figure 11 WCOS Example of Accumulated Work Operations

Figure 12, at special training centers with simulations of actual assembly lines, (a) training processes for assembly work, and (b) work training systems for assembly work are employed in the training of operators. Then, once a certain level of skills has been mastered, operators progress to actual assembly lines where they are promptly and methodically developed as highly skilled and experienced technicians using (c) standard work sheets extracted (Sakai and Amasaka, 2003).

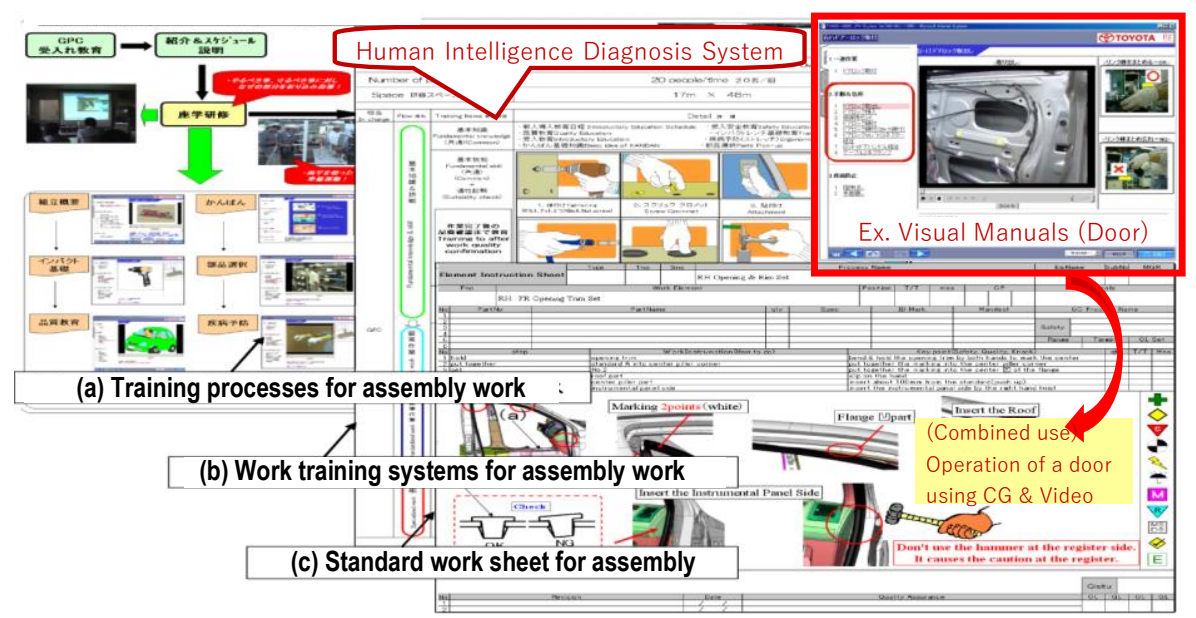

Figure 12 V-IOS Example for the Skill Strengthening of Operators using Virtual

(iii) AWD-COS constitutes a fundamental reform of work and labor named "Toyota's Epoch-Making Evolution in the Environment Model". In Figure 13, the author has initiated a company-wide project called Aging \& Work Development 6 Programs Project (AWD6P/J) in order to combat the effects of aging as follows; Project $\mathrm{I}$ is arousing motivation in workers, Project II is reviewing working styles to reduce fatigue, Project III is creating physical strength under the self-help efforts, Project IV is improving heavy work with user-friendly tools and equipment, Project $\mathrm{V}$ is creating thermal environments suited to the characteristics of assembly work, 


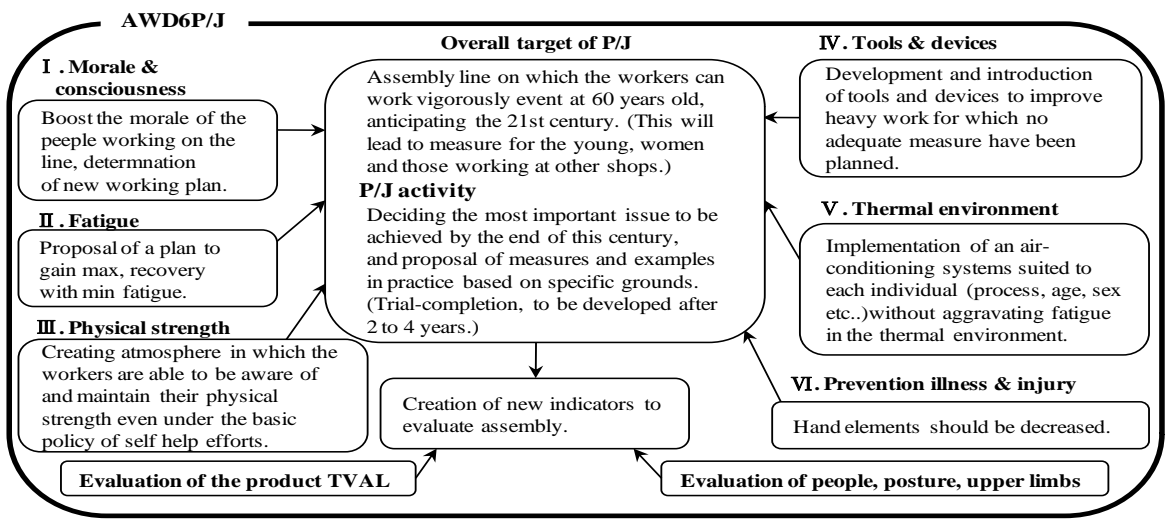

Figure 13 AWD-COS Example for the Aging \& Work Development 6 Programs

and Project VI is reinforcing illness and injury prevention (Amasaka et al., 2000c; Amasaka, 2004a, 2007c).

For example, Figure 14 illustrates a result of Project II activity as the "Study work of changing the rest pattern to reduce fatigue". In Figure 14(a), fatigue during operation gradually increases with time and decreases after each break shown in Normal Rest Pattern. In Figure 14(b), as the way to minimize fatigue, new 2 rest patterns (A \& B) were tested in order to analyze the difference with the fatigue level of Normal Rest Pattern. In Figure 14(c), a line stop was cut by half by the decrease in quality defects and human error (from these experimental effects, Toyota adopts a New Rest Pattern A in Japan and overseas at present).

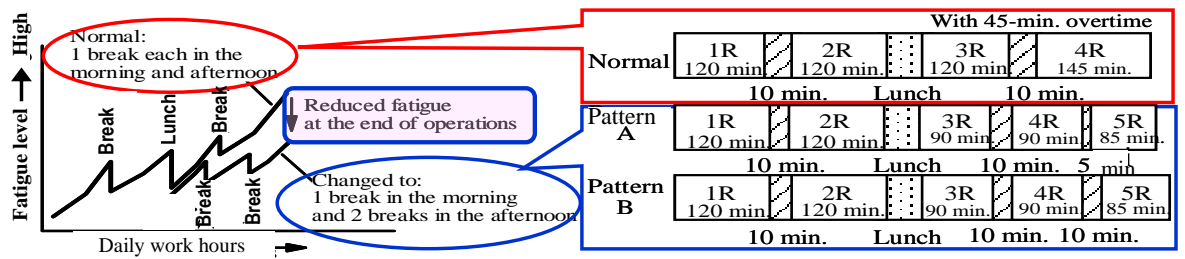

(a) Changed break time and effect

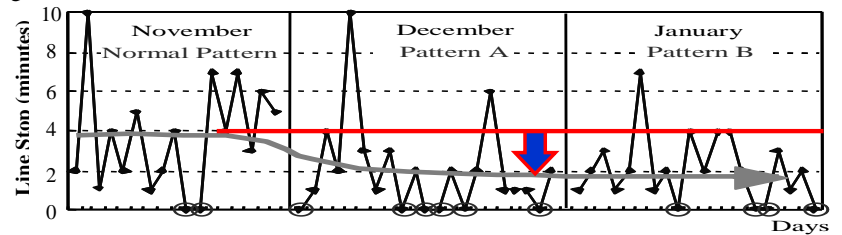

(c) Example of line stop time between 12:25 and 13:25 that causes work delays

Notes: Two assembly lines at Motomachi plant, where the Crown and IPSUM car models, were selected as experimental lines for 2-month trial. Fatigue level was calculated by both subjective and objective indicators (e.g., physiological).

Figure 14 Example of Project II-Study Work of Changing the Rest Pattern to Reduce Fatigue

Third, the author has established the TPS-QAS with two sub-systems-(i) QCIS and (ii) ARIM (Amasaka and Sakai, 1996, 1998, 2009) as follows:

(i) QCIS enables the development of manufacturing with superior quality and productivity by integrating the high-precision quality control systems. In Figure 
15(a), this illustrates a hardware system of trans-axle assembly line holding the (a) main-system, (b) sub-system, and connects (c) internal and external networks. In Figure 15(b), this shows a software system using intelligence quality control charts, and analyzes the diagnosis of process management abnormalities holding the (1) Scroll-function, (2) Display of grouped and raw data, (3) Hierarchical factorial analysis, (4) Kaizen, improvement of history database, (5) Abnormal diagnosis and (6) Data link with other application software.

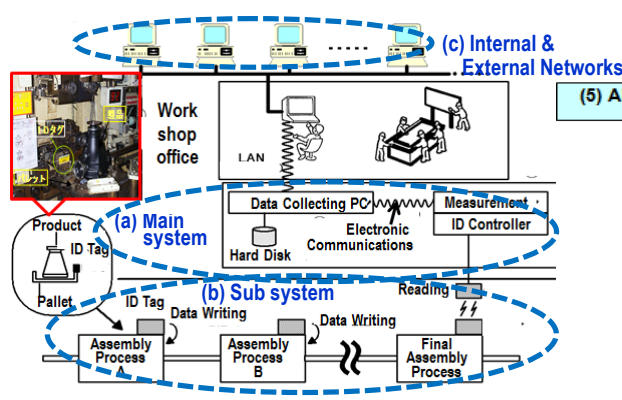

(a) Outline of hardware system ('Irans-axle unit)
Ex. Intelligence Quality Control Charts

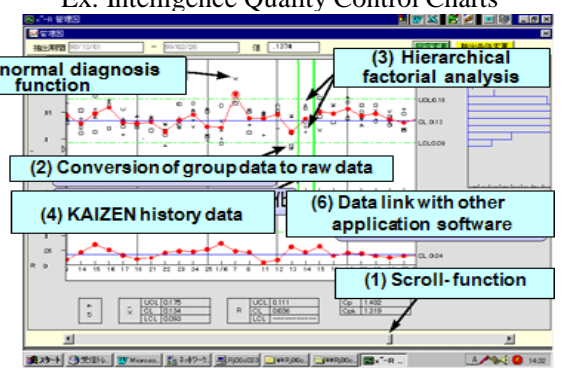

(b) Outline of software system

Figure 15 Example of QCIS Application using Quality Control Charts

(ii) ARIM enables the strengthen reliability analysis of facility operation and maintenance of information management. In Figure 16(a), this illustrates a hardware system for gathering the operating efficiency and failures using Andon system, and clusters of machinery on each production line in Japan and overseas. In Figure 16(b), for developing the preventive maintenance, this software system performs the Weibull analysis, failure diagnosis and failure life predicting employing Table 1 based on the reliability engineering.

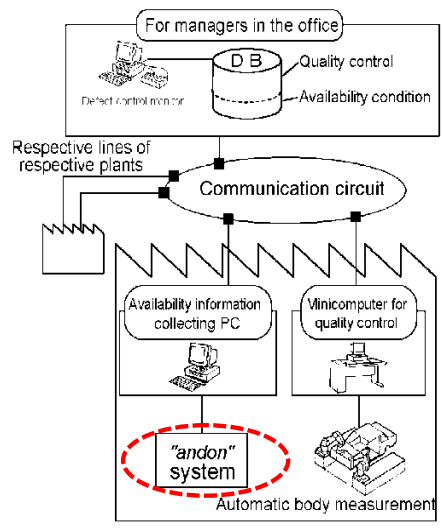

(a) Outline of hardware system
Table-1 Experience laws from Weible analysis result

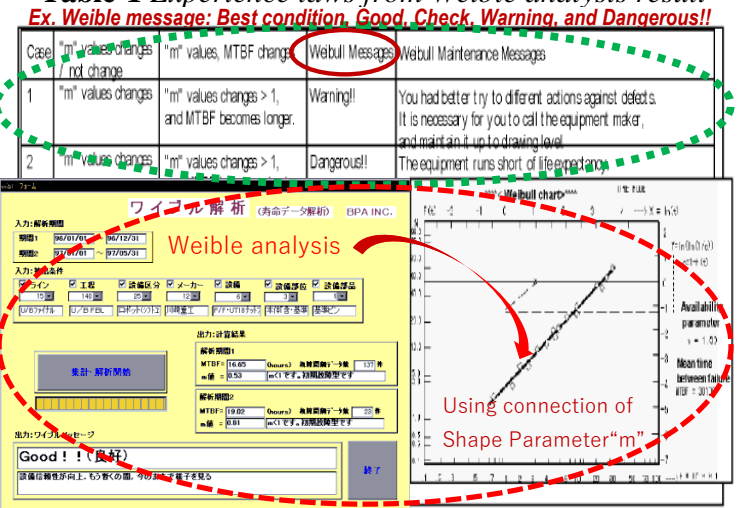

(b) Outline of software system using Weible analysis

Figure 16 Example of ARIM Application using Weible Analysis

\subsection{Innovation of Automobile Manufacturing Engineering based on the NJ- GGM}

(1) Improving the skills of experienced and inexperienced machine workers 
To develop IWV-IMM and WVEM based on the NJ-GGM, the author has clarified the factors involved in improving the skills of experienced and inexperienced machine workers engaged in typical lathe work with 6 processing stages of setup, rough cutting, semi finishing, making adjustments, finishing and completion by using S45C workpiece (Yanagisawa, et al., 2013).

Specifically, using electroencephalography (EEG) and statistical science, the physical and mechanical characteristics of a workpiece are those tensile strength, elongation, hardness, thermal conductivity, density, Young's modulus, shear elasticity modulus and yield strength, and the relative influence of these characteristics are clarified in accordance with the cutting conditions. Through these investigations, the author clarified the important criteria for making decisions based on the chip color and chip shape.

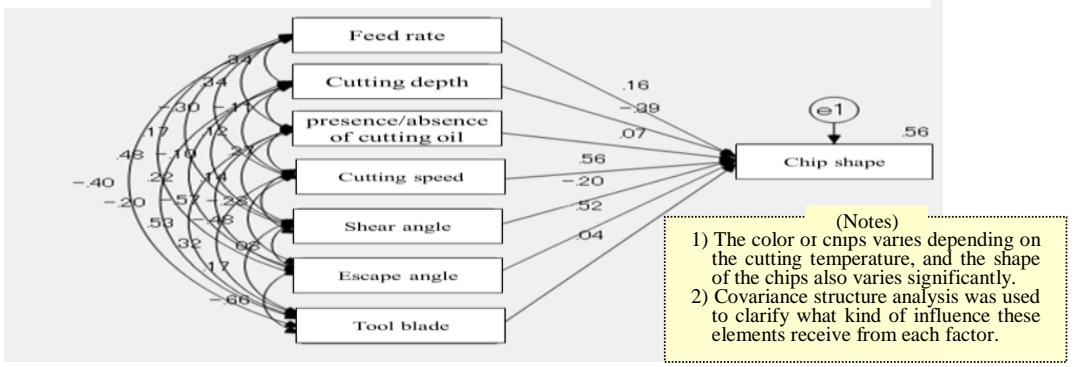

Figure 17 Chip Color during Finishing using Covariance Structure Analysis

For example, using covariance structure analysis, Figure 17 illustrates an example of clarifying factors for the "chip color during finishing" by experienced machine workers, and clarifies the influence these elements receive from each factor. This research clarifies points where inexperienced workers need guidance such as cutting tool selection, which is beneficial for both the person giving guidance and the person receiving guidance. Moreover, the author has investigated how intuition and knowhow make a difference between the skills of experienced and inexperienced workers based on the validity of other researches (Kawahara et al., 2016). These studies have contributed to technical training of inexperienced workers.

(2) Accelerated Technical Training System for the highly skilled operators

To realize the shortened training of highly skilled operators in auto-assembly line employing IWV-IMM and WVEM, the author has developed an Accelerated Technical Training System (ATTS) by development of HI-POS with HIA and HID above (Sakai and Amasaka, 2006b, 2007b, 2008; Amasaka et al., 2008). Specifically, ATTS contains the four sub-system of vehicle assembly process - (i) Assessment system of aptitude/inaptitude using aptitude test with eight categories of fundamental skills (: tightening, screw grommet, attachment, connector, hose, plug hole, tube and fitting), (ii) Optimization system of training steps with flowchart of training program, (iii) Skill training system for newly employed production operators, and (iv) Shortened training system for new overseas production operators.

In Figure 18, the author illustrates an application case of "Toyota's shortened training for the new overseas production operators" with four step program based on the courses during 5 courses during five days from "Day 1" to "Day 5"- Classroom 
lecture, Skill training, Dynamic training with simulating movement and Actual line training. The deployment of ATTS for training newly employed production operators at domestic and overseas manufacturing plants reduced the conventional training period by more than half, from two weeks to five days, leading the full-scale production to a good start. In this case, the launch of an overseas production plant, the target operating rate was achieved in four months after the start-up.

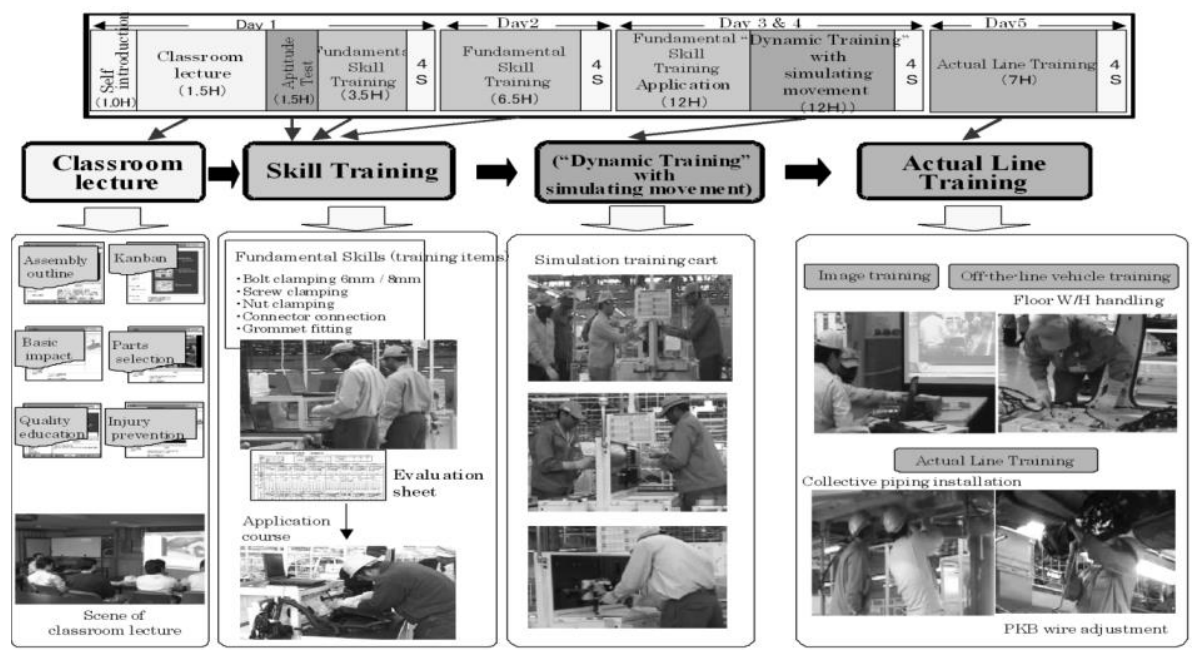

Figure 18 Toyota's Shortened Training for the New Overseas Production Operators in ATTS

(3) Global Intelligence Partnering Model for the global manufacturing strategy

To develop PPMM above, the authors has established the Global Intelligence Partnering Model (GIPM) for automobile global manufacturing strategy which improves the intellectual productivity of the affairs and management sections (Yamaji and Amasaka, 2007b).

Figure 19 shows the functions of the affairs and management sections as the corporate environment factors for succeeding in global marketing, customer-first, 1) $\mathrm{CS}$, ES and SS, for 2) high quality product and as a strategic factor to realize it, in order to 3) product reliability (high quality assurance) and corporation reliability (excellent company), and success in 4) intellectual productivity and human resource development. Moreover, 5) global production is realized by these. So the same quality and production at optimal locations are achieved. For that purpose, the highest priority was given to the "i) Intellectual information sharing" and "ii) Strategic Co-Creative Action" so that the "Strategic intelligence application system", and "Business process high linkage system" can effectively function.

To actualize GIPM, the author has developed the strategic application examples employing Toyota Supply System (TSS) as follows; (a) Creation of Automobile Exterior Design Model (AEDM) for raising customers' worth of world's prestige car "Lexus", (b) Improvement of "Paint corrosion resistance and protect plating parts from corrosion" for raising auto-unit-axle reliability, (c) Development of "Midfrequency tempering equipment using the heating coil of electromagnetic induction" and (d) "Automated straightening equipment" for the realizing high productivity of 
auto-unit-axle shaft, and (e) "New ceramic materials to the welding nozzle and welding tip" for the improving high operational availability of auto-unit-axle

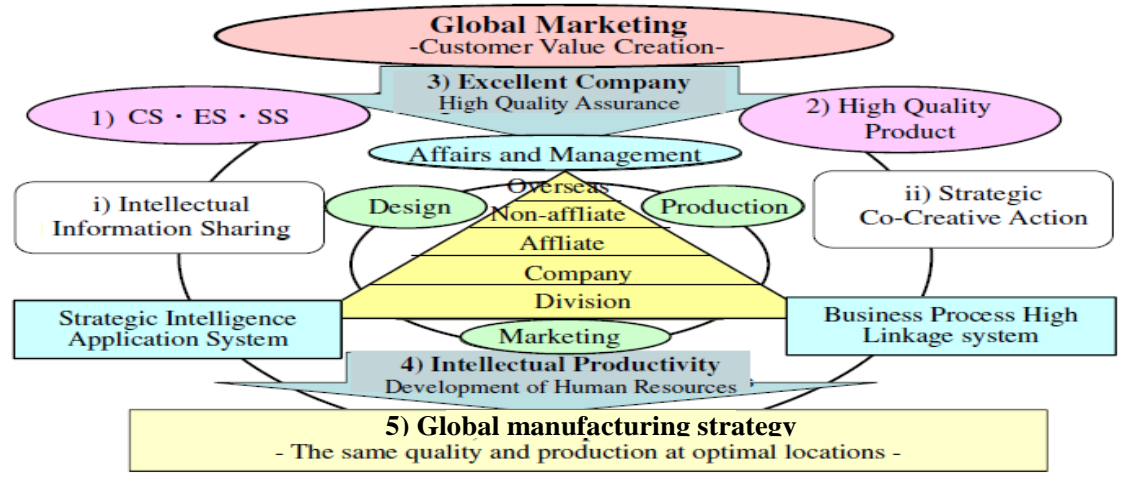

Figure 19 GIPM for the Global Manufacturing Strategy

housing" as the epoch-making improvement of QCD (Toyota, 1993; Amasaka, 2004b, 2009, 2018, 2019b).

(4) Strategic Cooperative Task Team Model for raising management technology

To strengthen promotion of SSTTM and SQM-PMM above, the author has structured the Strategic Cooperative Task Team Model (SCTTM) between the automaker and affiliated/non-affiliated suppliers as shown in Figure 20 (Amasaka, 2004a, 2008, 2017b). To purchase the necessary parts, it will be important for the manufacturer (maker) to mutually cooperate with (a) Supplier I (in-house parts maker (own company)), (b) Supplier II, affiliated maker (capital participation), (c) Supplier III, non-affiliated maker, and (d) Supplier IV, overseas maker (capital participation). In the actual deployment, it is important to strategically organize the stratified task teams for raising management technology as follows: (i) Product strategy, (ii) Engineering strategy, (iii) Quality strategy, (iv) QCD effect, (v) Value of the task teams, and (vi) Human resource strategy.

In SCTTM for the evolution of automobile manufacturing, the important job for the manufacturer's general administrator is to select jointly from his own company and suppliers: (1) Generators gifted with a special capacity for creating ideas, (2) Mentors having the ability to give guidance and advice, (3) Producers with the capability to achieve and execute, and (4) Promoters capable of implementing things as an organization. Then, as the key to successful SCTTM, the team leader

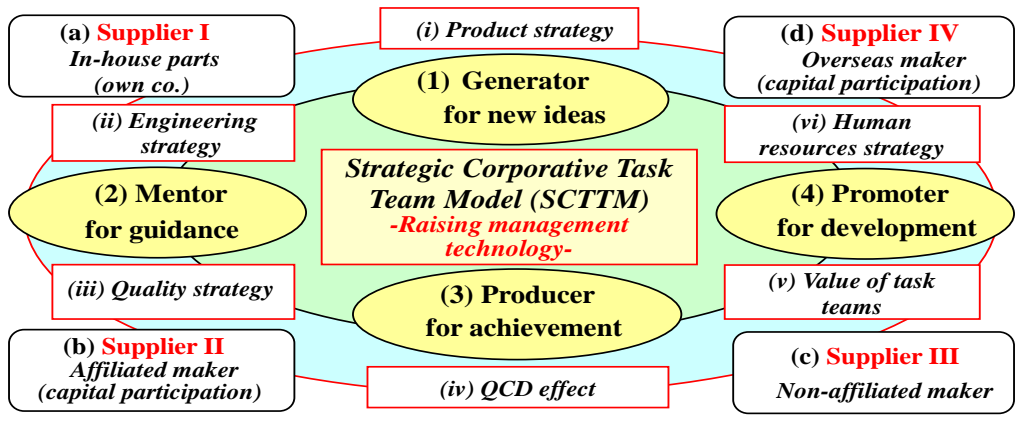

Figure 20 SCTTM for the Evolution of Japanese Automobile Manufacturing 
(administrator) should select the members who have at least one of the capabilities for (1) to (4), commission authority and responsibilities to the members, and has himself / herself concentrate on risk management.

To develop this, the author presents typical case studies as the improving of the bottleneck problems of worldwide auto-makers employing Toyota's Total Task Management Model (TTMTM) for realizing simultaneous QCD fulfilment (Amasaka, 2004a, 2017b). In Suppliers I, II and III, the author developed the establishment of "Brake pad quality assurance" using Total QA network activity (QAT) by Toyota, Aishin Seiki, Aishin Chemical and Akebono Brake Industry. The main objective is to establish a technology for attaining satisfactory braking performance while minimizing squeal through the result of sensitivity analysis on the causes of squeal and braking performance. The result of QAT is remarkable effects as follows; (i) Estimated market claim ratio reduction to $1 / 6$ (from $2.6 \%$ to $0.4 \%$ ), (ii) $\mathrm{In}$ process fraction defective: down $60 \%$ (from $0.5 \%$ to $0.2 \%$ ), (iii) Short convergence of initial failures: (from 9 months to 3 months), and (iv) Cost reduction: 9.4\% (156 Yen/unit).

Moreover, in other cases of Suppliers I-IV, the author was able to apply the SCTTM as follows; (i) TQM and SQC training for growing human resources of Toyota group in Japan and overseas, (ii) Specific engine fuel consumption improvement, (iii) High reliability assurance of the transaxle oil seal leakage, (iv) Rust preventive quality assurance of rod piston plating parts, (v) Various anti-rusting methods to various section of the vehicle body, (vi) Improvement of total curvature spring back in stamped parts with large curvature, (vii) Improving the reliability of body assembly line equipment, and (viii) Bolt-nut loosening solution by developing Automobile Optimal Product Design Model (AOPDM) (Toyota, 1993; Amasaka, 2004b, 2019a,b; Amasaka et al., 2012).

(5) New Global Partnering Production Model for expanding overseas manufacturing To develop IHS-AMPP using IWV-IMM and WVEM above, the author has established a New Global Partnering Production Model (NGP-PM) for Japan's expanding overseas manufacturing strategy as shown in Figure 21 (Ebioka et al., 2007; Amasaka and Sakai, 2010, 2011). The mission of NGP-PM is the simultaneous achievement of QCD in order to realize high quality assurance. The essential strategic policies include the following items: First of all, (A) establishment of a foundation for global production, "realization of global mother plants-advancement of Japanese production sites"; Second, (B) achieving the "independence of local production sites" through the incorporation of the unique characteristics (production systems, facilities, and materials) of both developing countries (Asia) and industrialized countries (US, Europe); Third, (C) necessity of developing intelligence operators to promote knowledge sharing among the production operators in Japan and overseas as well as for the promotion of higher skills and enhanced intelligence.

To actualize NGP-PM, it is essential to create a spiraling increase in the four core elements by increasing their comprehensiveness and high cycle-ization. Specifically, in realizing global mother plants, if Japanese and overseas manufacturing sites are to share knowledge from their respective viewpoints, the core elements must be advanced. To achieve this, a necessary measure is to design separate approaches suited to developing and industrialized countries. Concretely, in developing countries (1), the most important issue is increasing the autonomy of local manufacturing sites. 
At these sites, "training for highly skilled operators" that is suited to the manuallabor based manufacturing sites is the key to excellent QCD studies. Similarly, in industrialized countries (2), where manufacturing sites are based on automatization and increasingly high-precision equipment, "training of intelligence operators" resulting in "realizing highly reliable production control systems and ensuring high efficiency" is the key to excellent QCD studies. Moreover, production operators trained at "global mother plants" (3) can cooperate with operators at overseas production bases, and in order to generate synergistic results, can work to "localize global mother plants" in a way that is suited to the overseas production bases.

As the typical examples of NGP-PM deployment, the author describes the typical case studies of new integrated local production by partnering Toyota and overseas as follows; (i) New Turkish Production System (NTPS), an integration and evolution of Japanese and Turkish Production System, (ii) New Malaysia Production Model (NMPM), a new integrated production system of Japan and Malaysia, (iii) New Vietnam Production Model (NVPM), developing hybrid production of Japan and Vietnam, and (iv) Developing Advanced TPS at Toyota Manufacturing USA (Amasaka, 2007c, 2016; Yeap et al., 2010; Shan, et al., 2011: Miyashita and Amasaka, 2014, 2016). Deployment and validity of these studies are detailed to Amasaka (2015, 2017a, 2020b).

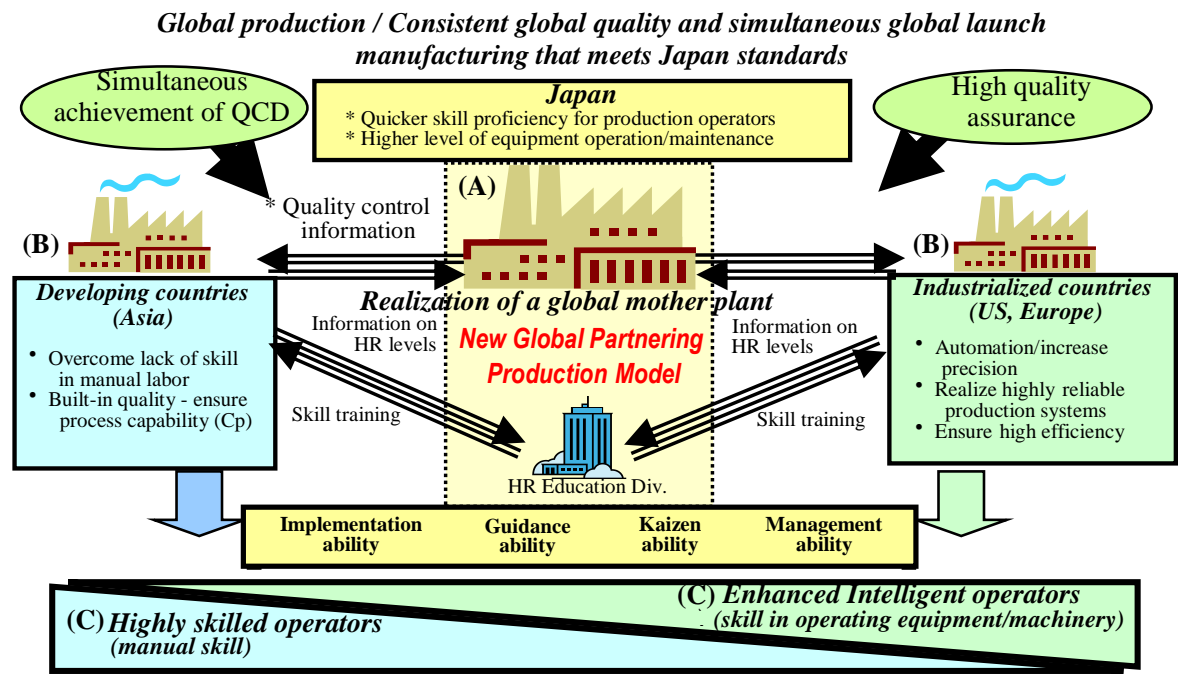

Figure 21 NGP-PM for Japan's Expanding Overseas Manufacturing Strategy

(6) Total Quality Assurance Networking Model for Toyota's new defect prevention To survive globalization and worldwide quality competition, Japanese manufacturing must work in order to shorten development times, ensure high quality and lower costs for the shift response to market changes (Amasaka, 2007a). To develop the IHS-AMPP above, therefore, the author has created the Total Quality Assurance Networking Model (TQA-NM) (Amasaka, 2004b; Kojima and Amasaka, 2011). In Figure 22, TQA-NM focuses on the subject of (A) Clear QA standards that make use of quantitative values (process capability, Cp), (B) Systematic use of know-how and experience resolving part issue, (C) Development of staff (workers) and managers 
familiar with the site, (D) QA tools for staff (workers) and managers and (E) Process

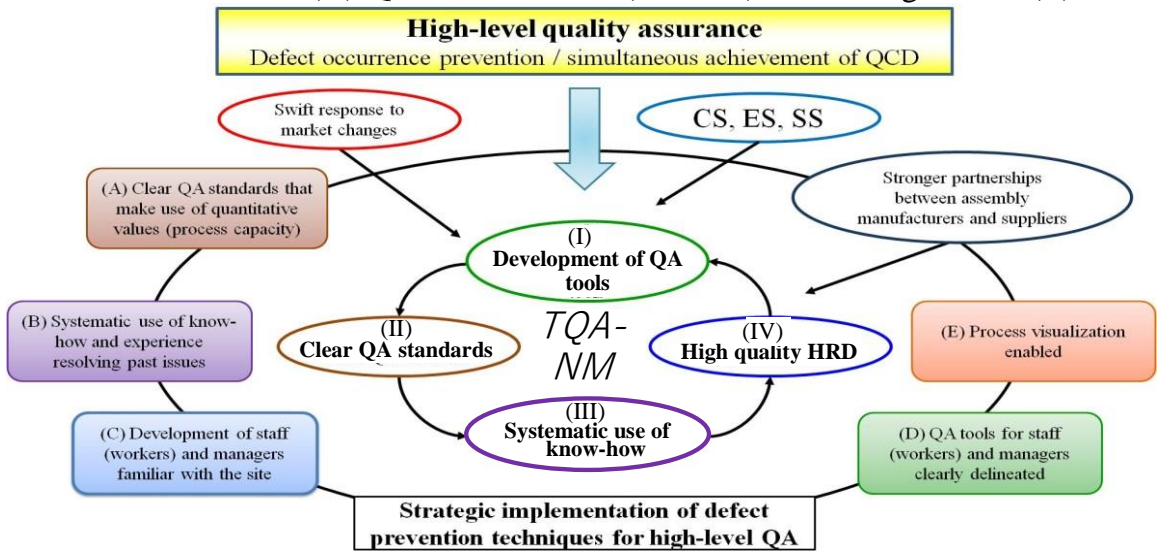

Figure 22 TQA-NM for Toyota's New Defect Prevention Technique

visualization enabled" which turned their attention especially to the "stronger partnerships between assembly manufacturers and suppliers".

Then, this model is done through the prevention of defect occurrence and by supporting the simultaneous achievement of QCD that come from strategically deploying a high-level quality assurance process as follows; (I) One of the technological components in achieving these goals is strengthening QA networks, and deploying QA tools, (II) Second is establishing clear quantitative QA standards that are not affected by worker experience, (III) Third is creating a system that can make use of worker expertise and information on past defects in an organized manner, and (IV) Fourth is the development of workers and frontline staff as the high quality HRD (Human Resource Development) who are familiar with the site.

To realize TQA-NM, specifically, the Total QA Networking Chart shown in Figure 23 is a defect occurrence prevention technique featuring a combination of QA tools. It also uses the Quality Function Deployment (QFD) or Failure Mode and Effect Analysis (FMEA), and matrix diagrams to deploy partnerships. The vertical axis identifies joint processes by suppliers and assembly manufacturers, from the

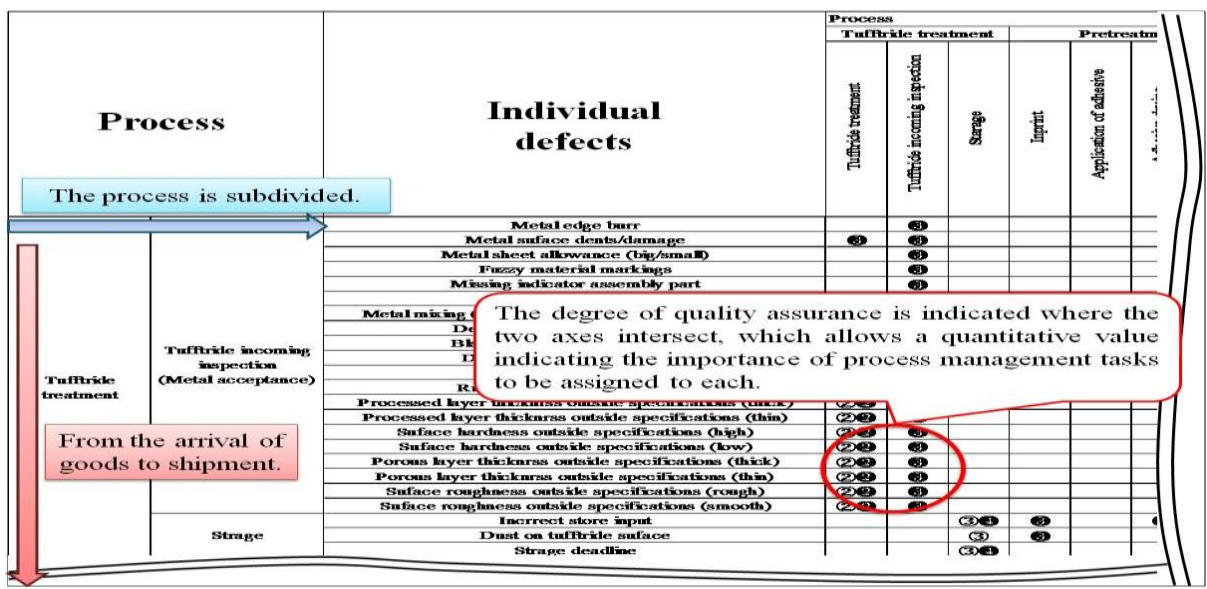

Figure 23 Example of the Total QA Networking Chart 
arrival of goods to shipment. The horizontal axis lists individual defects. The degree of QA is indicated where the two axes intersect, which allows a quantitative value indicating the importance of process management tasks to be assigned to each. Each process is comprehensively evaluated on the basis of what the defect occurrence prevention tasks are for that process and how highly they are ranked in terms of QA level using QA matrix. The task of this chart is ensured based on the "Ranking Occurrence and Outflow prevention", and is established a high-level QA system.

As the pioneering examples of TQA-NM deployment of Toyota and Toyota's SCM strategy, the author presents as follows; (i) Establishment of optimum casting conditions for compact DOHC cylinder head, (ii) Development of ferrite heat resistant cast steel, (iii) Measures to be taken for difficulties in the manufacture of aluminum die-casted head cover, (iv) Rust prevention quality assurance of plated components, (v) Improving the brake pads quality of trans-axle unit, (vi) CAE analysis for oil leakage mechanism of transaxle oil seal, and others (Toyota, 1993; Amasaka, 2004b, Amasaka Ed.,2012; Amasaka, et al., 2012). Deployment and validity of these studies are detailed to Amasaka (2015, 2017a, 2020b).

\section{Conclusion}

To re-construct world-leading management technologies, this study mentioned the evolution of Japan manufacturing foundation that surpasses conventional JIT practices. On a concrete target, the author focused on the strategic development of DGEM (Dual Global Engineering Model) possessing the NJ-GPM (New Japan Global Production Model) and NJ-GMM (New Japan Global Manufacturing Model) surpassing JIT. Concretely, the effectiveness of DGEM was verified through the actual applications to automobile manufacturing in Toyota and suppliers.

\section{Acknowledgement}

The author would like to acknowledge the generous support received from the following researchers: all those at the "Study group of 68QCS-Questionnaire analysis team of Toyota Group" in JUSE (Union of Japanese Scientists and Engineers), "Study group of the Ideal Situation the Quality Management of Manufacturing Industry" called Amasaka's Forum in JUSE, Toyota and other advanced assembly makers, many affiliated / nonaffiliated suppliers, and those connected with the Amasaka New JIT Laboratory at Aoyama Gakuin University that assisted with author's research, especially, Dr. Sakai, H., Mr. Yamaji, M., Mr. Ebioka, K., Yanagisawa, K., Kojima, T. and others.

\section{References}

1. Amasaka, K. (1988), "Concept and progress of Toyota Production System" (Plenary lecture), Co-sponsorship: Japan Society of Precision Engineering and others, Hachinohe, Aomori-ken, Japan. (in Japanese)

2. Amasaka, K. (2002), "New JIT, a new management technology principle at Toyota", International Journal of Production Economics, Vol. 80, pp. 135-144.

3. Amasaka, K. (2004a), "Development of Science TQM, a new principle of quality management: Effectiveness of strategic stratified task team at Toyota", International Journal of Production Research, Vol. 42(No. 7), pp. 3691-3706. 
4. Amasaka, K. (2004b), Science SQC, New Quality Control Principle: The quality strategy of Toyota, Tokyo: Springer-Verlag Tokyo.

5. Amasaka, K. (2007a), "New Japan Production Model, an advanced production management principle: Key to strategic implementation of New JIT", The International Business \& Economics Research Journal, Vol. 6(No. 7), pp. 6779.

6. Amasaka, K. (2007b), "High Linkage Model "Advanced TDS, TPS \& TMS": Strategic development of "New JIT" at Toyota", International Journal of Operations and Quantitative Management, Vol. 13(No. 3), pp. 101-121.

7. Amasaka, K. (2007c), “Applying New JIT-Toyota's global production strategy: Epoch-making innovation in the work environment, Robotics and ComputerIntegrated Manufacturing, Vol. 23(Issue. 3), pp. 285-293.

8. Amasaka, K. (2008), "Strategic QCD studies with affiliated and non-affiliated suppliers utilizing New JIT", Encyclopedia of Networked and Virtual Organizations, Vol. III(No. PU-Z), pp. 1516-1527.

9. Amasaka, K. (2009), "The foundation for advancing Toyota Production System utilizing New JIT", Journal of Advanced Manufacturing Systems, Vol. 80(No. 1), pp. 5-26.

10. Amasaka, K. (2014), "New JIT, new management technology principle", Journal of Advanced Manufacturing Systems, Vol. 13(No. 3), pp. 197-222.

11. Amasaka, K. (2015), New JIT, New Management Technology Principle, Boca Raton, USA: Taylor and Francis Group, CRC Press.

12. Amasaka, K. (2016), "Innovation of automobile manufacturing fundamentals employing New JIT: Developing advance Toyota Production System at Toyota Manufacturing USA", Proceedings of the $5^{\text {th }}$ Conference on Production and Operations Management, Habana International Conference Center, Cuba, pp. 1-10 (USB).

13. Amasaka, K. (2017a), Toyota: Production system, safety analysis and future directions, New York: NOVA Science Publishers.

14. Amasaka, K. (2017b), "Strategic Stratified Task Team Model for realizing simultaneous QCD fulfilment: Two case studies", The Journal of Japanese Operations Management and Strategy, Vol. 7(No. 1), pp. 14-35.

15. Amasaka, K. (2018), "Innovation of automobile manufacturing fundamentals employing New JIT: Developing Advanced Toyota Production System", International Journal of Research in Business, Economics and Management, Vol. 2(Issue. 1), pp. 1-15.

16. Amasaka, K. (2019a), "Studies on New Manufacturing Theory", Noble International Journal of Scientific Research, Vol. 3(No. 1), pp. 1-20.

17. Amasaka, K. (2019b), "Establishment of an Automobile Optimal Product Design Model: Application to study on bolt-nut loosening mechanism", Noble International Journal of Scientific Research, Vol. 3(No. 9), pp. 79-102.

18. Amasaka, K. (2020a), "Studies on New Japan Global Manufacturing Model: The innovation of manufacturing engineering", Journal of Economics and Technology Research, Vol. 1(No. 1), pp. 42-71.

19. Amasaka, K. (2020b), New Manufacturing Theory: Surpassing JIT, Norderstedt, Germany: Lambert Academic Publishing. 
20. Amasaka, K. Ed. (2007), New Japan Model"Science TQM"- Theory and practice for strategic quality management, Study group of ideal situation on quality management at manufacturing industry, Tokyo: Maruzen. (in Japanese)

21. Amasaka, K. Ed. (2012), Science TQM, new quality management principle: The quality management strategy of Toyota, Sharjah, UAE: Bentham Science Publishers.

22. Amasaka, K. Ed. (2019), Fundamentals of manufacturing industry management: New Manufacturing Theory - Operations management strategy 21C, Nagoya, Japan: Sankei-sha. (in Japanese)

23. Amasaka, K. et al. (1999), "The preliminary survey in 68QCS: Questionnaire result of TQM which creates Japan" (Special Lecture), Union of Japanese Scientists and Engineers, Hakone, Kanagawa-ken, Japan. (in Japanese)

24. Amasaka K. et al. (2000c), AWD6P/J Report of First Term Activity 1996-1999: Creation of 21C production line in which people over 60's can work vigorously, Toyota Motor Corporation, pp. 1-93. (in Japanese)

25. Amasaka, K., Ito, T. and Nozawa, Y. (2012), “A New Development Design CAE Employment Model", The Journal of Japanese Operations Management and Strategy, Vol. 3(No. 1), pp. 18-37.

26. Amasaka, K., Kurosu, S. and Morita, M. (2008), New Manufacturing Theory: Surpassing JIT - The evolution of Just-In-Time, Tokyo: Morikita-shuppan (in Japanese)

27. Amasaka, K. and Sakai, H. (1996), "Improving the reliability of body assembly line equipment", International Journal of Reliability, Quality and Safety Engineering, Vol. 3(No. 1), pp. 11-24.

28. Amasaka, K. and Sakai, H. (1998), “Availability and Reliability Information Administration System "ARIM-BL" by methodology of Inline-Online SQC", International Journal of Reliability, Quality and Safety Engineering, Vol. 5(No. 1), pp. 55-63.

29. Amasaka, K. and Sakai, H. (2009), "TPS-QAS, new production quality management model: Key to New JIT-Toyota's global production strategy", International Journal of Manufacturing Technology and Management, Vol. 18(No. 4), pp. 409-426.

30. Amasaka, K. and Sakai, H. (2010), "Evolution of TPS fundamentals utilizing New JIT strategy-Proposal and validity of Advanced TPS at Toyota", Journal of Advanced Manufacturing Systems, Vol. 9(No. 2), pp. 85-99.

31. Amasaka, K. and Sakai, H. (2011), "The New Japan Global Production Model "NJ-GPM": Strategic development of Advanced TPS", The Journal of Japanese Operations Management and Strategy, Vol. 2(No. 1), pp. 1-15.

32. Doos, D., Womack, J. P. and Jones, D. T. (1991), The Machine that Change the World - The Story of Lean Production, New York: Rawson / Harper Perennial.

33. Ebioka, K., Sakai, H., Yamaji, M. and Amasaka, K. (2007), "A New Global Partnering Production Model "NGP-PM" utilizing Advanced TPS", Journal of Business \& Economics Research, Vol. 5(No. 9), pp. 1-8

34. Hayes, R. H. and Wheelwright, S. C. (1984), Restoring Our Competitive Edge: Competing through Manufacturing, Hoboken, USA: Wiley.

35. Kawahara, F., Kogane, Y., Amasaka, K. and Ouchi, N. (2016), “A skill map based on an analysis of experienced workers' intuition and knowhow", IOSR Journal of Business and Management, Vol. 18(Issue. 12), pp. 80-85. 
36. Kozaki, T., Oura, A. and Amasaka, K. (2012), "Establishment of TQM Promotion Diagnosis Model "TQM-PDM" for strategic quality management", China-USA Business Review, Vol. 10(No. 11), pp. 811-819.

37. Kojima, T. and Amasaka, K. (2011), "The Total Quality Assurance Networking Model for preventing defects: Building an effective quality assurance system using a Total QA Network", International Journal of Management \& Information Systems. Vol. 15(No. 3), pp.1-10.

38. Miyashita, S. and Amasaka, K. (2014), "Proposal of a New Vietnam Production Model (NVPM), a new integrated production system of Japan and Vietnam", IOSR Journal of Business and Management, Vol. 16(Issue. 12), pp. 18-25.

39. Ohno, T. (1977), Toyota Production System, Tokyo: Diamond-sha.(in Japanese)

40. Sakai, H. and Amasaka, K. (2003), "Construction of "V-IOS" for promoting intelligence operator: Development and effectiveness for visual manual format", The Japan Society for Production Management, The $18^{\text {th }}$ Annual Conference, Nagasaki Institute of Applied Science, Nagasaki, Japan, pp. 173-176. (in Japanese)

41. Sakai, H. and Amasaka, K. (2005), "V-MICS, Advanced TPS for strategic production administration: Innovative maintenance combining DB and CG", Journal of Advanced Manufacturing Systems, Vol. 4(No. 6), pp. 5-20.

42. Sakai, H. and Amasaka, K. (2006a), "TPS-LAS Model using process layout CAE system at Toyota, Advanced TPS: Key to global production strategy New JIT”, Journal of Advanced Manufacturing Systems, Vol. 5(No. 2), pp. 1-14.

43. Sakai, H. and Amasaka, K. (2006b), "Strategic HI-POS, intelligence production operating system: Applying Advanced TPS to Toyota's global production strategy", WSEAS Transactions on Advances in Engineering Education, Vol. 3(No. 3), pp. 223-230.

44. Sakai, H. and Amasaka, K. (2007a), "The robot reliability design and improvement method and Advanced Toyota Production System", International Journal of Industrial and Service Robotics, Vol. 34(No. 4), pp. 310-316.

45. Sakai, H. and Amasaka, K. (2007b), "Human digital pipeline method using total linkage through design to manufacturing", Journal of Advanced Manufacturing Systems, Vol. 6(Issue. 2), pp. 101-113.

46. Sakai, H. and Amasaka, K. (2008), "Human-Integrated Assist Systems for intelligence operators", Encyclopedia of Networked and Virtual Iorganizations, Vol. II(No. G-Pr), pp. 678-687.

47. Shan, H., Yeap, Y. S. and Amasaka, K. (2011), "Proposal of a New Malaysia Production Model "NMPM": A new integrated production system of Japan and Malaysia", Proceedings of International Conference on Business Management 2011, Miyazaki Sangyo-Keiei University, Miyazaki, Japan, pp. 235-246.

48. Taylor, D. and Brunt, D. (2001), Manufacturing Operations and Supply Chain Management - Lean Approach, Boston, USA: Thomson Learning.

49. Toyota Motor Corporation. (1993), Toyota Technical Review: SQC at Toyota, Vol. 43, Special issue, pp. 1-172 (hosted by Amasaka, K.). (in Japanese)

50. Tsunoi, M., Yamaji. M. and Amasaka, K. (2010), "A study of building an Intellectual Working Value Improvement Model, IWV-IM”, International Business \& Economics Research Journal, Vol. 9(No. 11), pp. 79-84. 
51. Uchida, K., Tsunoi, M. and Amasaka, K. (2012), "Creating Working Value Evaluation Model, WVEM", International Journal of Management \& Information Systems, Vol. 16(No. 4), pp. 299-306.

52. Womack, J. P., Jones, D. and Roos. D. (1990), The machine that change the world - The story of Lean Production, New York: Rawson/Harper Perennial.

53. Womack, J. P. and Jones, D. T. (1994), "From Lean Production to the Lean Enterprise", Harvard Business Review, March-April, pp. 93-103.

54. Yamaji, M., Sakai, H. and Amasaka, K. (2007a), "Evolution of technology and skill in production workplaces utilizing Advanced TPS", The Journal of Business \& Economics Research, Vol. 5(No. 6), pp. 61-68.

55. Yamaji, M. and Amasaka, K. (2007b), "Proposal and validity of Global Intelligence Partnering Model for Corporate Strategy, GIPM-CS", International IFIP-TC 5.7 Conference on Advanced in Production Management System, Linkoping, Sweden, Springer, pp. 59-67.

56. Yamaji, M., Sakatoku, T. and Amasaka, K. (2008), "Partnering Performance Measurement "PPM-AS" to strengthen corporate management of Japanese automobile assembly makers and suppliers", International Journal of Electronic Business Management, Vol. 6(No. 3), pp. 139-145.

57. Yanagisawa, K., Yamazaki, M., Yoshioka, K. and Amasaka, K. (2013), "Comparison of experienced and inexperienced machine workers", International Journal of Operations and Quantitative Management, Vol. 19(No. 4), pp. 259274.

58. Yeap, Y, S., Murat. M. S. and Amasaka. K. (2010), "Proposal of New Turkish Production System, NTPS: Integration and evolution of Japanese and Turkish Production System", Journal of Business Case Study, Vol. 6(No. 6), pp. 69-76.

\section{About Our Author}

Kakuro Amasaka is a professor in the Graduate School of Science and Engineering at Aoyama Gakuin University, Japan in April, 2000. He received his Ph.D. degree in Precision Mechanical and System Engineering, Statistics and Quality Control from Hiroshima University, Japan, in 1997. After joining Toyota Motor Corp., Japan, in 1968, Dr. Amasaka worked as the consultant of TQM and SQC for many divisions, and the General Manager of TQM Promotion Div. (1998-2000). His specialty is Science SQC, Science TQM, New JIT, New Manufacturing Theory, Customer Science and Kansei Engineering. He has been serving as the president of JOMSA (Japanrse Operations Management and Strategy Association, 2011-2012). Now, Dr. Amasaka is a professor emeritus of Aoyama Gakuin University (2016-present), and is inaugurated as the representatives of JOMSA (2008-present). 